\title{
A patient with pycnodysostosis presenting with seizures and porencephalic cysts
}

\author{
Subhash Kumar \\ Department of Radiodiagnosis, All India Institute of Medical Sciences, Patna, Bihar, India
}

\begin{abstract}
Pycnodysostosis is a rare autosomal recessive disorder caused by mutations in the cysteine protease Cathepsin K gene located on chromosome 1q21. It has a well characterized skeletal phenotype which include short stature, generalized increased bone density with propensity of fractures, open calvarial sutures and fontanelle, dental abnormalities, obtuse mandibular angle, resorption of lateral end of clavicle, acro-osteolysis, and in some cases visceromegaly. Central nervous system involvement is very rare and porencephalic cysts has been reported only once, the cause being hypothesised to be an imbalance between the growing brain, its vascular supply and intraventricular fluid pressure. We had a patient with bilateral frontal lobe porencephalic cysts; the patient presenting with complex partial seizures. Cathepsins have been found to be involved in neurological diseases and role of proteases has been well established in gliosis.
\end{abstract}

Key words: Cathepsin K, porencephalic cyst, porencephaly, pycnodysostosis, seizures

\section{Introduction}

Pycnodysostosis is a rare autosomal recessive disorder caused by mutations in the gene encoding the cysteine protease Cathepsin K. ${ }^{[1]}$ It has a well characterized skeletal phenotype, ${ }^{[2]}$ but rarely reported central nervous system involvement. Porencephalic cysts in pycnodysostosis have been described only once previously and its cause proposed to be an imbalance between the brain growth and its vascular supply and a normal but unopposed cerebrospinal fluid pressure..$^{[3]}$ Recent genetic advances however provide more insight into the involvement of the brain.

\section{Case Report}

An 18 year old male, $2^{\text {nd }}$ child out of five from a non-consanguineous marriage, presented with recurrent

\begin{tabular}{|l|l|}
\hline \multicolumn{2}{|c|}{ Access this article online } \\
\hline Quick Response Code: & Website: \\
\hline & www.ruralneuropractice.com \\
\cline { 2 - 2 } & \\
\hline
\end{tabular}

episodes of right sided complex partial seizures for last three years. Initial frequency of seizures was 1-2 per month which had increased to 3-4 per month at the time of presentation. No history of trauma or other significant medical or surgical illnesses was present. There was no history of seizure disorder or dwarfism in his family. On examination he was of short stature (4 feet and 4 inches) and underweight $(25 \mathrm{~kg}$ ) with a normal upper-lower segment ratio, normal arm span and normally developed secondary sexual characters. He had normal mental and memory functions and had no sensory and motor abnormalities. No cranial nerve deficits were present. Hematological examination was normal and an ultrasonographic exam of abdomen was normal as well. MRI of the brain showed bilateral frontal lobe porencephalic cysts [Figure 1]. Radiographs and plain CT scan of the head revealed generalized increased bone density [Figure 2]. Obtuse angle of mandible and dental crowding were noted [Figure 2a]. The calvarial sutures and fontanelle were wide open with presence of multiple Wormian bones in the region of the lambda [Figure 2b]. The skull base was also sclerotic [Figure 2c]. The vertebrae were spool shaped [Figure 2d] and there was presence of acro-osteolysis [Figure $2 \mathrm{e}$ and $\mathrm{f}$ ]. The thoracic cage was narrow [Figure $2 \mathrm{~g}$ ]. Bone within bone appearance or Erlenmeyer flask deformity of the long bones were not seen [Figure $2 \mathrm{~h}]$.

Address for correspondence:

Dr. Subhash Kumar, 103, Type IV, Block 2, All India Institute of Medical Sciences, AlIMS Residential Complex, Hydraulic, Khagaul, Patna - 801 105, Bihar, India. E-mail: drsubhash.dm@gmail.com 


\section{Discussion}

Pycnodysostosis is a rare autosomal recessive disorder first described in $1962^{[4]}$ and its gene mapped to chromosome 1q21 in 1995. ${ }^{[5]}$ It is caused by mutations in Cathepsin K gene, a cysteine protease highly expressed in osteoclasts. ${ }^{[1]}$ Apart from the classical diagnostic features of short stature with fragile sclerotic bones, obtuse mandibular angle, acro-osteolysis, hypoplastic clavicles (not seen in the present case - Figure 2g), and open cranial sutures and fontanelles with the presence of

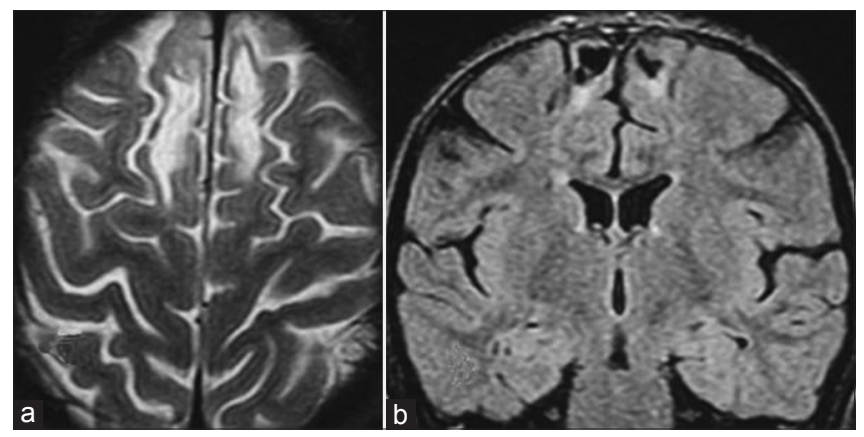

Figure 1: (a) Axial T2W and (b) Coronal FLAIR images show bilateral frontal lobe porencephalic cysts multiple Wormian bones, other features include ${ }^{[1,6,7]}$ thick calvaria, hypoplastic paranasal sinuses, relative proptosis and beaked nose, persistence of deciduous teeth, with premature or delayed eruption of permanent teeth, causing crowding and double row of teeth. Also seen are tooth misalignment, enamel hypoplasia, and a grooved palate. ${ }^{[6]}$ Trunk deformities like kyphosis, scoliosis, and a narrow chest are seen. Patients may present with frequent fractures, recurrent dental abscesses or sleep apnea ${ }^{[6]}$ although our patient did not have any of these and had presented with complex partial seizures which has not been reported earlier. Usually there are no visceral manifestations, although cases of extra medullary hematopoiesis and hepato-splenomegaly have been reported. ${ }^{[8]}$

A variety of neurological abnormalities have been described in the various skeletal dysplasias however; pycnodysostosis seems to have been spared at large. ${ }^{[9]}$ Porencephalic cysts have been reported only once earlier. ${ }^{[3]}$ The authors proposed that the persistence of open sutures and fontanelles allows the normal but unopposed intra-ventricular fluid pressure to progressively distend the brain parenchyma.
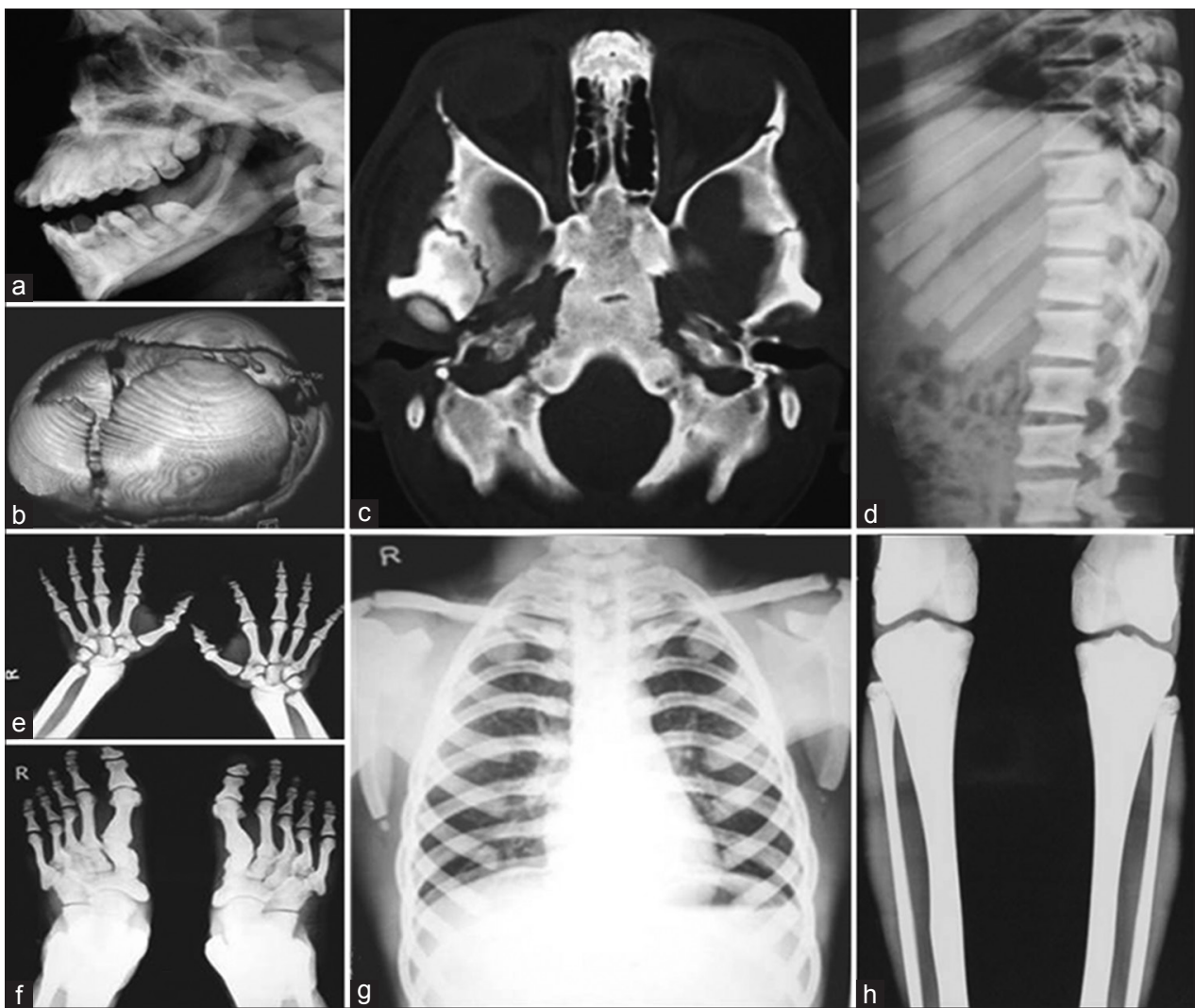

Figure 2: (a) X-ray showing obtuse gonial angle and crowded teeth (b) CT head showing open sutures and fontanelle with multiple Wormian bones (c) Axial CT head, showing sclerosed skull base (d) Dorsolumbar spine X-ray showing sclerosed, spool shaped vertebrae (e) X-ray both hands and (f) Feet showing acro-osteolysis (g) Narrow chest; the clavicles do not appear hypoplastic in this case (h) X-ray both legs, showing sclerosed long bones; there is no 'bone within bone appearance' or 'Erlenmeyer flask deformity' thus differentiating from osteopetrosis. Also see the supplementary file 
Thus a state of imbalance is created between the enlarging brain and its vascular supply resulting in the porencephalic cyst. This simplistic explanation gets a little complicated by the genetic information added over the last few years. Among all the various cathepsins, the Cathepsin K protease, whose deficiency is considered responsible for pycnodysostosis, is the most potent mammalian elastase yet described. In adults, it is generously distributed in various tissues such as bone, heart, lung, spleen, kidney, liver, thymus, intestine and pancreas, arterial smooth muscle cells, synoviocytes, breast carcinoma cells, endometrium, thyroid epithelial cells, multinucleated giant cells, etc., although it is predominantly expressed in osteoclasts and macrophages. ${ }^{[1,10]}$ Parenchymal microglial cells are uncommitted myeloid progenitors of immature dendritic cells and macrophages and match their Cathepsin profile. ${ }^{[11]}$ Considering that the role of microglia has been established in gliosis, it is not hard to surmise a more direct interrelation between pycnodysostosis and gliotic changes in brain. Neuronal death has been found to be associated with Cathepsins $\mathrm{B}$ and $\mathrm{L}^{[12]}$ but not Cathepsin $\mathrm{K}$ which is not overtly expressed in brain. However, there is an interplay between the various protease ${ }^{[13]}$ and Cathepsin K has been found to be associated with schizophrenia. ${ }^{[14]} \mathrm{A}$ skeletal dysplasia with known cerebral abnormalities including porencephaly is the oculo-facial-digital syndrome. ${ }^{[15]}$ which is caused by a mutation in CXORF5 gene, located on Xp22.3-22.2. OFD I protein, which is essential for foetal survival and early development of the mouth, face, hands and feet is entirely different form the Cathepsins.

A better understanding of the molecular events responsible for pycnodysostosis, gliosis, porencephalic cysts and the role of cathepsin $\mathrm{K}$ in the nervous system is thus required, especially so since trials of anti-cathepsin drugs are underway in an attempt to treat osteoporosis.

\section{Acknowledgments}

Dr. NK Mishra, Prof and Head, and Dr. SB Gaikwad, Prof, Department of Neuroradiology, AIIMS, New Delhi.

\section{References}

1. Gelb BD, Shi GP, Chapman HA, Desnick RJ. Pycnodysostosis, a lysosomal disease caused by cathepsin K deficiency. Science 1996;273:1236-8.

2. Elmore SM. Pycnodysostosis: A review. J Bone Joint Surg Am 1967;49:153-61.

3. Figueiredo J, Reis A, Vaz R, Leáo M, Cruz C. Porencephalic cyst in pycnodysostosis. J Med Genet 1989;26:782-4.

4. Maroteaux P, Lamy M. Deux observations d'une affection osseuse condensante: La pycnodysotose. Arch Franc Ped 1962;19:267-74.

5. Gelb BD, Edelson JG, Desnick RJ. Linkage of pycnodysostosis to chromosome 1q21 by homozygosity mapping. Nat Genet 1995;10:235-7.

6. Fleming KW, Barest G, Sakai O. Dental and facial bone abnormalities in pyknodysostosis: CT findings. AJNR Am J Neuroradiol 2007;28:132-4.

7. Meredith SC, Simon MA, Laros GS, Jackson MA. Pycnodysostosis. A clinical, pathological, and ultramicroscopic study of a case. J Bone Joint Surg Am 1978;60:1122-7.

8. Kozlowski K, Yu JS. Pycnodysostosis. A variant form with visceral manifestations. Arch Dis Child 1972;47:804-7.

9. Lachman RS. Neurologic abnormalities in the skeletal dysplasias: A clinical and radiological perspective. Am J Med Genet 1997;69:33-43.

10. Motyckova G, Weilbaecher KN, Horstmann M, Rieman DJ, Fisher DZ, Fisher DE. Linking osteopetrosis and pycnodysostosis: Regulation of cathepsin K expression by the microphthalmia transcription factor family. Proc Natl Acad Sci USA 2001;98:5798-803.

11. Santambrogio L, Belyanskaya SL, Fischer FR, Cipriani B, Brosnan CF, Ricciardi-Castagnoli $\mathrm{P}$, et al. Developmental plasticity of CNS microglia. Proc Natl Acad Sci U S A 2001;98:6295-300.

12. Felbor U, Kessler B, Mothes W, Goebel HH, Ploegh HL, Bronson RT, et al. Neuronal loss and brain atrophy in mice lacking cathepsins B and L. Proc Natl Acad Sci U S A 2002;99:7883-8.

13. Punturieri A, Filippov S, Allen E, Caras I, Murray R, Reddy V, et al. Regulation of elastinolytic cysteine proteinase activity in normal and cathepsin K-deficient human macrophages. J Exp Med 2000;192:789-99.

14. Bernstein HG, Bukowska A, Dobrowolny H, Bogerts B, Lendeckel U. Cathepsin K and schizophrenia. Synapse 2007;61:252-3.

15. Wood BP, Young LW, Townes PL. Cerebral abnormalities in the oral-facial-digital syndrome. Pediatr Radiol 1975;3:130-6.

How to cite this article: Kumar S. A patient with pycnodysostosis presenting with seizures and porencephalic cysts. J Neurosci Rural Pract 2014;5:284-6.

Source of Support: Nil. Conflict of Interest: None declared. 